\title{
Faktor-faktor yang Mempengaruhi Harga Kain Tenun Songket (Lotis) di Desa Oabikase Kecamatan Insana Barat
}

\author{
Yudith Maria Sonbay ${ }^{\mathrm{a}}$ \\ ${ }^{a}$ Fakultas Pertanian, Universitas Timor, Kefamenanu, TTU-NTT, Indonesia.
}

\section{Article Info}

\section{Article history:}

Received 2 Maret 2018

Received in revised form 22 Juni 2018

Accepted 16 Juli 2018

\section{DOI:}

https://doi.org/10.32938/ag.v3i3.229

Keywords:

Harga

Tenun

Songket

\begin{abstract}
Abstrak
Penelitian ini bertujuan untuk mengetahui gambaran umum pembuatan kain tenun songket serta mengetahui faktor-faktor yang mempengaruhi harga kain tenun songket di Desa Oabikase Kecamatan Insana Barat Kabupaten Timor Tengah Utara. Penelitian dilaksanakan pada bulan Februari sampai bulan Juli 2017. Penentuan sampel dilakukan secara Purposive sampling dengan pertimbangan responden memproduksi kain tenun songket pada tahun 2016, sehingga dari $80 \mathrm{KK}$ yang memproduksi kain tenun songket di Desa Oabikase diambil 50 responden. Analisis data dalam penelitian ini meliputi analisis deskriptif kualitatif dan analisis regresi linear berganda. Hasil penelitian menunjukkan pembuatan kain tenun songket terdiri dari penggulungan benang, mengurutkan benang (Non), Naet dan menenun (Теnu). Secara simultan faktor harga produk saingan, pengalaman menenun, pendidikan formal, besaran permintaan, biaya produksi berpengaruh nyata pada harga kain tenun, dengan memiliki nilai sebesar $F_{\text {hitung }}=38,09>F_{\text {tabel }} 2,09$ pada taraf kepercayaan $10 \%$. Secara parsial faktor-faktor yang berpengaruh pada harga kain tenun songket pada taraf kepercayaan $10 \%$ adalah faktor harga produk saingan dengan nilai $t_{\text {hitung }}$ sebesar $1,80>$ nilai $t_{\text {tabel }}$ sebesar 1,30 , faktor besaran permintaan dengan nilai $t_{\text {hitung }}$ sebesar $1,35>$ nilai $t_{\text {tabel }}$ sebesar 1,30 dan faktor biaya produksi dengan nilai $t_{\text {hitung }}$ sebesar $9,97>$ nilai $t_{\text {tabel }}$ sebesar 1,30 .
\end{abstract}

\section{Pendahuluan}

Masyarakat Indonesia dikenal sebagai masyarakat yang kaya akan keberagaman budaya. Salah satunya ditandai dengan adanya cara berpakaian dengan motif yang berbeda-beda. Oleh karena itu hal yang paling berpengaruh terhadap cara berpakaian ialah bahan dasar yang digunakan. Meski secara administratif gugusan-gugusan wilayah pulau tersebut berada di bawah satu pemerintahan namun tak berarti budayanya juga homogen. Tiap wilayah dan suku masing-masing mempunyai keunikan yang khusus dibanding dengan daerah, contohnya seperti menampilkan legenda, mitos dan hewan masing masing daerah. Kain tenun songket merupakan hasil dari menenun benang sehingga menghasilkan kain. Songket atau lotis adalah sebuah seni yang sangat indah, sebagai generasi muda kita harus melestarikan seni songket yang dipercayai memiliki beraneka ragam motif yang dipercaya mengandung makna dan falsafah tertentu. Menurut Damanik $d k k$., (2018) kerajinan tenun songket banyak dijalankan kaum perempuan dengan alat produksi berupa alat tenun bukan mesin (ATBM)

Masyarakat Kabupaten Timor Tengah Utara (TTU) kaya akan keberagaman kebudayaan. Di antara kekayaan akan kebudayaan itu adalah tenun songket dengan aneka corak (motif) yang memiliki makna filosofis yan dalam. Seni tenun dalam masyarakat Kabupaten TTU layaknya bunga, dan taman kreativitas yang simultan. Karya seni ini merupakan salah satu karya yang unik dan mengagumkan, karena di samping menggambarkan kearifan, kreativitas dan kemajuan masyarakat setempat, juga mengandung nilai-nila kemanusiaan universal. Nilai-nilai agama dan kebudayaan loka mengarahkannya menjadi simbol dalam bentuk busana yang melambangkan kemuliaan pemakainya. Kehormatan seseorang, di antaranya dilihat dari mode busana yang dikenakan. Di sini busana, dalam taraf tertentu, menjadi alat identifikasi moralitas, karakter dan bahkan status seseorang atau kelompok. Bagi masyarakat Kabupaten TTU, pakaian tidak semata-mata berfungsi untuk melindungi tubuh dari panas dan hujan, lebih dari itu pakaian berfungsi untuk menutup malu, menjemput budi, menjunjung adat, menolak bala, dan menjunjung bangsa. Karenanya, busana tak hanya bernilai pragmatis, tetapi juga bernilai religius, adat dan kultural, etis dan estetis (Usfinit, 2003) Selanjutnya menurut Ulung, (2013) tenun songket merupakan seni budaya di belahan benua Asia yang berasal dari daratan China.

Kecamatan Insana Barat merupakan salah satu kecamatan di Kabupaten TTU dengan jumlah penduduk yang cukup padat dengan keadaan masyarakat adalah heterogen dan tingkat perekonomian yang beragam. Di Kecamatan Insana Barat, Desa Oabikase para ibu rumah tangga pada umumnya dapa mengusaha pembuatan kain tenun songket, namun masih tradisional. Hal in dapat dilihat pada alat-alat yang digunakan, SDM dan modal awal yang sangat terbatas. Produksi kain tenun songket di Desa Oabikase terhitung dari tahun 2014-2016 berfluktuasi. Pada tahun 2014 produksi kain tenun songket sebanyak 75 kain pada tahun 2015 produksi kain tenun songket sebanyak 72 kain dan pada tahun 2016 produksi kain tenun songket sebanyak 48 kain. Dari hasil observasi pada Desa Oabikase terdapat masalah harga yang tidak efisien dalam usaha tenunnya karena pendapatan masyarakat pada tahun 2014 sebesar Rp11.250.000,00, pada tahun 2015 sebesar Rp10.800.000,00 dan pada tahun 2016 sebesar Rp7.200.000,00.

Kondisi ini menunjukkan bahwa harga benang yang tinggi dan produksi kain tenun songket yang membutuhkan waktu yang sangat lama namun harga tidak sesuai dengan yang diharapkan. Harga kain tenun songket bervariasi dan berfluktuasi. Faktor-faktor yang mempengaruhi harga kain tenun songket belum dapat ditentukan sehingga perlu dilakukan kajian tentang faktor-faktor yang mempengaruhi harga kain tenun songket (Lotis) di desa Oabikase kecamatan Insana Barat. Menurut Kompas Cyber Media, (2012) Lotis merupakan perpaduan dari kain tenun dengan gaya sulam. Tampilannya mirip dengan tenun songket. Proses pembuatannya mirip dengan tenun Buna dimana benang harus diberi warna lebih dulu. Perajin tenun lotis biasanya akan melakukan dua pekerjaan sekaligus, yaitu menenun dan menyulam beberapa motif, sehingga dalam satu kain akan terlihat motif seperti tiga dimensi karena jahitan yang agak menonjol keluar.

Penelitian ini bertujuan untuk mengetahui gambaran umum kain tenun songket serta mengetahui faktor-faktor yang mempengaruhi harga kain tenun songket di Desa Oabikase Kecamatan Insana Barat, Kabupaten TTU.

\section{Metode}

Penelitian dilaksanakan di Desa Oabikase Kecamatan Insana Bara Kabupaten TTU pada bulan Februari sampai dengan bulan Juli 2017 dengan mengambil data tahun 2016. Penelitian menggunakan metode survei. Data yang dikumpulkan berupa data primer dan sekunder. Data primer adalah datadata yang diperoleh melalui wawancara dengan responden dan observasi. Data sekunder merupakan data yang diperoleh dari instansi-instansi terkait. Pengambilan sampel dilakukan dengan metode purposive sampling sesuai petunjuk Sutrisno, (2004) yaitu dari populasi $80 \mathrm{KK}$ yang diambil 50 responden. Pertimbangannya adalah responden memproduksi kain tenun pada tahun 2016

Untuk mengetahui gambaran umum pembuatan kain tenun songket dilakukan secara deskriptif kualitatif sesuai petunjuk Sugiyono, (2006), sedangkan untuk menganalisis faktor-faktor yang mempengaruhi harga digunakan regresi berganda sesuai petunjuk Gujarati \& Porter, (2009) dengan formula $Y=a+b_{1} X_{1}+b_{2} X_{2}+b_{3} X_{3}+b_{4} X_{4}+b_{5} X_{5}+e$, dimana:

$\mathrm{Y} \quad=$ Harga kain tenun $(\mathrm{Rp})$

a Konstanta

$\mathrm{b}_{1}-\mathrm{b}_{5}=$ Koefisien variabel

$\mathrm{X}_{1} \quad=$ Harga produk saingan $(\mathrm{Rp})$

$\mathrm{X}_{3} \quad=$ Pendidikan (tingkatan)

$\mathrm{X}_{4} \quad=$ Besaran permintaan (jumlah kain)

$\mathrm{X}_{5} \quad=$ Biaya produksi $(\mathrm{Rp})$

Analisis data dilakukan menggunakan bantuan aplikasi SPSS.16 yang dilakukan sesuai petunjuk Santoso, (2008)

\section{Hasil dan Pembahasan}

\subsection{Pembuatan Kain Tenun Songket}

Pembuatan kain tenun songket menggunakan cara-cara tradisional dengan alatalatnya pun masih tradisonal dan pembuatan kain tenun biasanya hanya dilakukan oleh wanita saja dan motif kain tenun berbeda-beda sesuai daerah dari pembuat kain tenun. Langkah-langkah pembuatan kain tenun sebagai berikut:

a. Penggulungan Benang

Proses pembuatan kain tenun songket didahului dengan proses penggulungan benang, dan penggulungan benang dilakukan tanpa alat penggulung dan dilakukan secara tradisional, penggulungan benang pada sebuah batu yang dilapisi kertas dan benang digulung secara bulat.

b. Mengurutkan Benang (Non)

Proses yang kedua yaitu mengurutkan benang atau dalam istilah dawannya non, dan proses ini dilakukan secara tradisional dengan menggunakan bambu dengan ukuran $\pm 2 \mathrm{~m}$ yang disebut Neke yang berfungsi untuk memasang tali untuk dapat memikat Atis, dan Atis disandarkan pada dua tiang pendek. Sianaek dipasang silang pada tali yang sudah di pasang pada Neke dan Atis dan yang terakhir adalah memasang Ut, Puapau dengan Puat dan mulai mengurutkan benang (Non)
$\mathrm{X}_{2} \quad=$ pengalaman menenun (tahun) 
c. Naet

Proses ini adalah proses awal pembentukan motif sebelum penenunan dan proses Naet menggunakan Monaf dan lidi untuk menahan benang-benang yang masih belum terbentuk, motif yang dibentuk berasal dari benang dua warna oleh karena itu dibutuhkan Hau bekot untuk menyokong benang agar membentuk sebuah motif yang diinginkan.

d. Menenun (Tenu)

Proses yang terakhir adalah proses menenun dan proses menenun dibutuhkan waktu selama dua minggu untuk menghasilkan kain tenun songket dengan motif yang diinginkan dan motif yang sering dibentuk adalah motif bunga, Beb'kataf, motif tokek ataupun motif lainnya sesuai keinginan penenun dan dari 80 kepala benang, diperoleh satu kain tenun songket dengan ukuran panjang 140 meter dan lebar 1 meter.

\subsection{Faktor-faktor yang Mempengaruhi Harga Kain Tenun Songket}

a. Hubungan Antara Variabel

Hubungan antara variabel dilihat pada nilai korelasi variabel tersebut jika nilai korelasi $\geq 0,8$ maka variabel tersebut memiliki korelasi yang erat dan jika $\leq 0,8$ maka variabel tersebut memiliki korelasi yang lemah. Hasil analisis korelasi sebagaimana pada Tabel 1. menunjukkan bahwa hubungan antara variabel bebas semuanya memiliki nilai $<0,8$ maka dapat dikatakan bahwa tidak ada hubungan yang serius antara variabel bebas yang digunakan dalam penelitian ini.

Tabel 1. Matriks Korelasi

\begin{tabular}{ccccccc}
\hline Correlation & $\mathrm{Y}$ & $\mathrm{X}_{1}$ & $\mathrm{X}_{2}$ & $\mathrm{X}_{3}$ & $\mathrm{X}_{4}$ & $\mathrm{X}_{5}$ \\
\hline $\mathrm{Y}$ & 1 & & & & & \\
$\mathrm{X}_{1}$ & 0,588 & 1 & & & & \\
$\mathrm{X}_{2}$ & $-0,161$ & $-0,007$ & 1 & & & \\
$\mathrm{X}_{3}$ & 0,055 & 0,026 & $-0,727$ & 1 & & \\
$\mathrm{X}_{4}$ & 0,149 & 0,150 & 0,051 & $-0,002$ & 1 & \\
$\mathrm{X}_{5}$ & 0,859 & 0,541 & $-0,224$ & 0,143 & 0,048 & 1 \\
\hline
\end{tabular}

b. Koefisien Determinasi $\left(\mathrm{R}^{2}\right)$

Koefisien determinasi menunjukkan besar kontribusi variabel bebas terhadap variabel terikat dalam model persentase (\%).

Tabel 2. Koefisien Determinasi $\left(\mathrm{R}^{2}\right)$

\begin{tabular}{cccc}
\hline Model & $\mathrm{R}$ & $\mathrm{R}$ Square & Adjusted R Square \\
\hline 1 & 0,901 & 0,812 & 0,791 \\
\hline
\end{tabular}

Berdasarkan Tabel 2. dapat dikatakan bahwa koefisien determinasi atau $\mathrm{R}$ Square $\left(\mathrm{R}^{2}\right)$ dalam model di atas memiliki nilai 0,812 yang mana kontribusi variabel bebas yang terdiri dari harga produk saingan $\left(\mathrm{X}_{1}\right)$, pengalaman menenun $\left(\mathrm{X}_{2}\right)$, pendidikan formal $\left(\mathrm{X}_{3}\right)$, besaran permintaan $\left(\mathrm{X}_{4}\right)$ dan biaya produksi $\left(\mathrm{X}_{5}\right)$ terhadap variabel terikat yaitu harga tenun songket $(\mathrm{Y})$ sebesar $81,2 \%$ dan sisa kontribusi sebesar $18,8 \%$ adalah model dari variabel bebas yang tidak diakomodir dalam penelitian ini.

c. Pengaruh Secara Simultan

Berdasarkan Tabel 3. diketahui bahwa secara bersama-sama faktor harga produk saingan $\left(\mathrm{X}_{1}\right)$, pengalaman menenun $\left(\mathrm{X}_{2}\right)$, pendidikan formal $\left(\mathrm{X}_{3}\right)$, besaran permintaan $\left(\mathrm{X}_{4}\right)$ biaya produksi $\left(\mathrm{X}_{5}\right)$ berpengaruh nyata pada harga kain tenun songket, dengan memiliki nilai $\mathrm{F}_{\text {hitung }}=38,099>\mathrm{F}_{\text {tabel }} 2,09$ atau probabilitas $0,000<\alpha=10 \%(0,10)$.

Tabel 3. Anova Regresi

\begin{tabular}{lllllll}
\hline Model & $\begin{array}{l}\text { Jumlah } \\
\text { Kuadrat }\end{array}$ & df & $\begin{array}{l}\text { Rerata } \\
\text { Kuadrat }\end{array}$ & $\mathrm{F}_{\text {hitung }}$ & Sig. & $\mathrm{F}_{\text {tabel }}$ \\
\hline Regression & 2,04710 & 5 & 4,0949 & 38,099 & 0,000 & $(10 \%)$ \\
Residual & 4,7289 & 44 & 1,0758 & & & 2,09 \\
\cline { 1 - 5 } Total & 2,52010 & 49 & & & & \\
\hline
\end{tabular}

d. Pengaruh Secara Parsial

Berdasarkan Tabel 4. diperoleh persamaan regresi berganda yakni $\mathrm{Y}=$ $12342,585+0,038 \mathrm{X}_{1}-84,565-743,904 \mathrm{X}_{3}+2714,120 \mathrm{X}_{4}+0,820 \mathrm{X}_{5}$.

Tabel 4. Koefisien Regresi

\begin{tabular}{|c|c|c|c|c|c|c|}
\hline \multirow{2}{*}{ Model } & \multicolumn{2}{|c|}{$\begin{array}{l}\text { Unstandardized } \\
\text { Coefficients }\end{array}$} & \multirow{2}{*}{$\begin{array}{c}\begin{array}{c}\text { Standardized } \\
\text { Coefficients }\end{array} \\
\text { Beta } \\
\end{array}$} & \multirow{2}{*}{$\mathrm{t}_{\text {hitung }}$} & \multirow{2}{*}{ Sig } & \multirow{2}{*}{$\begin{array}{c}t_{\text {tabel }} \\
(10 \%)\end{array}$} \\
\hline & B & Error & & & & \\
\hline (Constant) & 12342,585 & 20597,254 & & 0,599 & 0,552 & \\
\hline $\begin{array}{l}\text { Harga Produk } \\
\text { Saingan (X1) }\end{array}$ & 0,038 & 0,021 & 0,143 & 1,806 & 0,078 & \\
\hline $\begin{array}{l}\text { Pengalaman } \\
\text { (X2) }\end{array}$ & $-84,565$ & 154,495 & $-0,054$ & $-0,547$ & 0,587 & \\
\hline $\begin{array}{l}\text { Pendidikan } \\
\text { Formal (X3) }\end{array}$ & $-743,904$ & 705,597 & $-0,101$ & $-1,054$ & 0,298 & 1,303 \\
\hline $\begin{array}{l}\text { Besaran } \\
\text { Permintaan } \\
\text { (X4) }\end{array}$ & 2714,120 & 2009,107 & 0,089 & 1,351 & 0,184 & \\
\hline $\begin{array}{l}\text { Biaya } \\
\text { Produksi (X5) }\end{array}$ & 0,820 & 0,082 & 0,805 & 9,977 & 0,000 & \\
\hline
\end{tabular}

Berdasarkan Tabel 4. juga dapat dilakukan pemetaan untuk mengetahui pengaruh secara sendiri-sendiri variabel bebas terhadap variabel terikat pada uji satu arah dengan taraf kepercayaan $\alpha=10 \%(0,10)$ dengan nilai $t_{\text {tabel }}$ sebesar 1,30 , yang mana nilai $t_{\text {tabel }}$ tersebut berlaku untuk semua variabel bebas yang diakomodir dalam penelitian ini.

- Harga Produk Saingan $\left(\mathrm{X}_{1}\right)$

Harga produk saingan yang dimaksudkan dalam penelitian ini adalah produk sejenis kain tenun namun bukan kain tenun songket dan produk saingan itu adalah kain tenun ikat, dan kain tenun dari Biboki yang harganya berkisar antara Rp300.000,00 sampai Rp500.000,00. Berdasarkan hasil analisis data diketahui nilai $t_{\text {hitung }}$ dari faktor harga produk saingan sebesar $1,80>$ nilai $t_{\text {tabel }}$ sebesar 1,30 maka hipotesis diterima artinya bahwa faktor harga produk saingan memiliki pengaruh yang nyata terhadap harga kain tenun songket.

- Pengalaman Menenun $\left(\mathrm{X}_{2}\right)$

Pengalaman menenun dalam penelitian ini adalah pengalaman menenun kain tenunan songket dan hasil penelitian diketahui bahwa kisaran pengalaman menenun antara 6-65 tahun. Berdasarkan hasil analisis data diketahui bahwa nilai $t_{\text {hitung }}$ dari faktor pengalaman menenun sebesar $-0,54<t_{\text {tabel }}$ sebesar 1,30 berarti hipotesis ditolak artinya bahwa faktor pengalaman tidak memiliki pengaruh terhadap harga dari kain tenun songket dengan nilai probabilitas $0,587>0,10(10 \%)$. Semakin banyak pengalaman berarti umur semakin bertambah hal ini mempengaruhi fisik dari responden semakin bertambahnya umur yang semakin menurunnya kemampuan melihat terutama dalam usaha tenunan, kain tenun dibutuhkan kejelian mata dalam mengurutkan benang dan membentuk motif dari kain tenun itu sendiri.

- Pendidikan Formal $\left(\mathrm{X}_{3}\right)$

Pendidikan dalam penelitian ini adalah jenjang pendidikan formal yang dilalui responden namun dari hasil penelitian diketahui bahwa semakin tingg pendidikan maka akan mempengaruhi pertimbangan dalam mempertahankan harga dengan waktu bekerja, dan semakin bertahan harga maka produksi kain tenun makin lama terjual. Berdasarkan hasil analisis data diketahui bahwa nilai $\mathrm{t}_{\text {hiung }}$ sebesar $-1,05<$ nilai $\mathrm{t}_{\text {tabel }} 1,30$ dan kesimpulannya hipotesis ditolak artinya bahwa faktor pendidikan tidak berpengaruh terhadap harga kain tenun songket. Hal ini dilihat pula dengan tingkat pendidikan yang dilalui oleh penenun kain tenun songket yang sebagian besarnya hanya menempuh pendidikan sampai tingkat sekolah dasar dan sebagian tidak bersekolah.

- Besaran Permintaan $\left(\mathrm{X}_{4}\right)$

Hasil penelitian diketahui bahwa besaran permintaan kain tenun songket berkisar antara 2 sampai 4 potong kain tenun songket dan permintaan kain tenun songket ini tergantung dari selera konsumen. Berdasarkan hasil analisis data diketahui nilai $t_{\text {hitung }}$ sebesar $1,35>$ nilai $t_{\text {tabel }}$ sebesar 1,30 dan kesimpulannya hipotesis diterima artinya bahwa faktor besaran permintaan mempengaruhi harga dari kain tenun songket. Semakin banyak permintaan maka harga semakin meningkat dan sebaliknya bahwa semakin rendah permintaan maka harga yang ditawarkan pun semakin menurun.

$\circ$ Faktor Biaya Produksi $\left(\mathrm{X}_{5}\right)$

Biaya produksi terdiri dari biaya variabel dan biaya tetap (penyusutan alat) dan dari hasil perhitungan diperoleh total biaya produksi kain tenun songket sebesar Rp12.663.616,00 dengan rata-rata biaya produksi sebesar Rp253.272,00.

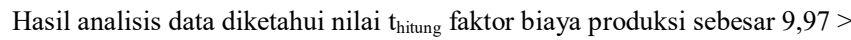
nilai $t_{\text {tabel }}$ sebesar1,30 dan kesimpulannya hipotesis diterima artinya bahwa adanya pengaruh dari faktor biaya produksi terhadap harga kain tenun songket. Biaya merupakan dasar dalam penentuan harga, sebab suatu tingkat harga yang tidak dapat menutup biaya produksi akan mengakibatkan kerugian. Sebaliknya, apabila suatu tingkat harga melebihi semua biaya akan menghasilkan keuntungan, di lokasi penelitian bahwa biaya produksi lebih kecil dari harga produk kain tenun songket atau lotis.

\section{Simpulan}

Pembuatan kain tenun songket terdiri dari penggulungan benang, mengurutkan benang (Non), Naet dan menenun (Tenu). Secara simultan faktor harga produk saingan, pengalaman menenun, pendidikan formal, besaran permintaan, biaya produksi berpengaruh nyata pada harga kain tenun, dengan memiliki nilai sebesar $F_{\text {hitung }}=38,09>F_{\text {tabel }} 2,09$ pada taraf kepercayaan $10 \%$. Secara parsial faktor-faktor yang berpengaruh pada harga kain tenun songket pada taraf kepercayaan $10 \%$ adalah faktor harga produk saingan dengan nilai $t_{\text {hitung }}$ sebesar $1,80>$ nilai $t_{\text {tabel }}$ sebesar 1,30 , faktor besaran permintaan dengan nilai $t_{\text {hitung }}$ sebesar $1,35>$ nilai $t_{\text {tabel }}$ sebesar 1,30 dan faktor biaya produksi dengan nilai $t_{\text {hitung }}$ sebesar $9,97>$ nilai $t_{\text {tabel }}$ sebesar1,30 sedangkan faktor lainnya tidak berpengaruh pada harga kain tenun songket.

\section{Pustaka}

Damanik, J., Rindrasih, E., Cemporaningsih, E., Marpaung, F., Raharjana, D.T., Brahmantya, H. \& Wijaya 2018. Membangun Pariwisata dari Bawah. Yogyakarta: UGM Press.

Gujarati, D.N. \& Porter, D.C. 2009. Basic Econometrics. McGraw-Hill Irwin. Kompas Cyber Media 2012. Kekayaan Kain Tenun Nusa Tenggara Timur. KOMPAS.com. Tersedia di [Diakses 11 November 2017].

Santoso, S. 2008. Panduan Lengkap Menguasai Spss 16. Jakarta: Elex Media Komputindo. 
Sugiyono, 2006. Metode Penelitian Kuantitatif, Kualitatif dan $R \& D$ Bandung: Alfabeta.

Sutrisno, H. 2004. Metodologi Research: Untuk Menulis Laporan, Skripsi, Thesis dan Disertasi. Yogyakarta: Andi Offset.

Ulung, G. 2013. Seri Bacpacking \& Traveling - Charming Sumatera Barat Jakarta: Gramedia Pustaka Utama.

Usfinit, A.U. 2003. Maubes-Insana: Salah Satu Masyarakat di Timor dengan Struktur Adat yang Unik. Yogyakarta: Kanisius. 